\title{
Male and Community Involvement in Birth Preparedness and Complication Readiness in Benin City, Southern Nigeria
}

\author{
Obi $\mathrm{AI}^{1}, \mathrm{Abe}^{2}$, Okojie $\mathrm{OH}^{1,3}$ \\ ${ }^{1}$ Department of Community Health, University of Benin Teaching Hospital, PMB 1111 , Benin City, Edo State. \\ ${ }^{2}$ Department of Primary Health Care, Edo State Ministry of Health \\ ${ }^{3}$ Department of Community Health, University of Benin, PMB 1154, Benin City, Edo State.
}

\begin{abstract}
Background: The role of men in maternity care in Africa is understudied. Their role is pivotal with appropriate community framework for the success of any maternal health initiative. This study was conducted to assess male and community involvement in birth preparedness and complication readiness in Benin City.

Study Design: A descriptive cross sectional study design was utilized for this study.

Results: Two hundred and thirty seven consenting spouse/male respondents participated in the study. The study showed that male attendance at ANC was 33(13.9\%) with 32 (97.0\%) accompanying their wives sometimes and 1(3.0\%) always for ANC. Furthermore, 127(55.0\%) male respondents accompanied their partners during labour. Community involvement in BPACR was 17(6.7\%), with community transport services $14(82.4 \%)$ being the predominant form of community support.
\end{abstract}

Conclusion: Male and community involvement in BPACR was low in this study. Better involvement is required through advocacies and setting up of community support structures such as transport scheme and community health insurance schemes to enhance emergency fund savings for improved maternal care.

Key words: Benin City, Birth preparedness and complication readiness, Community and Male involvement.

\section{Introduction}

In sub-Saharan Africa, pregnancy and childbirth continue to be viewed as solely a woman's issue. ${ }^{1}$ A male companion at antenatal care is rare and in many communities, it is unthinkable to find male companions accompanying a woman to the labour room during delivery. ${ }^{1}$

Studies carried out in El Salvador ${ }^{2}$, Greece ${ }^{3}$ showed low male involvement in antennal care and labour; these studies showed low levels of male participation $(34 \%)$ in prenatal care, delivery and postnatal care attendance. Delivery $(81 \%)$ was the most attended by fathers in El Salvador ${ }^{2}$ with low participation of Greek fathers in labour and infant care attributable to personal decision and due to Hospital policy. ${ }^{3}$

In addition, low (32.1\%) male participation was identified in a study in Northern Nigeria ${ }^{4}$ as very little preparation was made for skilled assistance during delivery (6.2\%), saving as emergency funds $(19.5 \%)$ and transportation plan $(24.2 \%)$.

In contrast to the above high levels of male involvement $68.6 \%$ were identified in Uganda ${ }^{5}$ as pregnant women who had birth plans were more likely to be accompanied by their spouse for antenatal clinic attendance and labour. Furthermore, another Ugandan study ${ }^{1}$ showed that $42.9 \%$ of women reported to have been accompanied by their spouses during labour, while $41.4 \%$ of them said their spouses remained at home looking after the children, and $25 \%$ helped with household chores during the antenatal period.

Similarly, other studies in Osun ${ }^{6}$ and $\mathrm{Oyo}^{7}$ South Western Nigeria, showed a high level of male involvement as high level of male knowledge and participation in pregnancy and labour were identified, as $53.2 \%$ of the male respondents had high level of knowledge of emergency obstetric conditions (danger signs) ${ }^{6}$ and $72.5 \%$ of the male respondents accompanied their wife to the health facility for delivery, $63.9 \%$ were present at the last deliver and $97.4 \%$ encouraged their wives to attend antenatal clinic by way of paying antenatal service bills, paying transport fare to the clinic and reminding their spouse of their clinic visits.

Finally, an Indian study ${ }^{16}$ revealed a low level of community participation in birth preparedness and complication readiness, the main support was in the area of transportation and only $18.6 \%$ of the respondents studied affirmed that the community made special arrangement for transportation for pregnant women during emergency situations.

Male involvement in maternal health is key to ensuring considerable reduction in maternal mortality. This study was conducted to ascertain male and community involvement in Birth preparedness and complication readiness strategy as important support structures to help reduce delays in accessing maternal health care especially during emergencies. 


\section{Materials and Methods}

A descriptive cross sectional study was conducted involving 237 consenting spouse/male partners of pregnant women in Benin City. Benin City is the capital of Edo State and comprising Egor, Oredo and IkpobaOkha LGAs respectively. ${ }^{9}$ Benin City has a large number of public and private health institutions that offer a wide range of primary, secondary and tertiary health care services including maternal health services such as antenatal and post natal care services to its populace with some pregnant women patronizing the services of traditional birth attendants. Notable health institutions in Benin City include the University of Benin Teaching Hospital, Uselu Psychiatric Hospital, Central Hospital Benin, Stella Obasanjo Women and Child Hospital, Military Hospital, Airforce Base Hospital, Faith Mediplex, St Philomena Catholic Hospital among others just to mention a few ${ }^{10}$

The study was conducted from February 2012 to June 2013. The sample size was calculated using Cochran's formulae for descriptive study ${ }^{11}$ based on a $72.5 \%$ prevalence of male attendance during delivery from a previous study ${ }^{7}$. Respondents were selected using multistage sampling technique across the three LGAs that made up Study area and final respondents were recruited by simple random sampling using a table of random numbers.

Researcher administered pretested closed and open ended semi-structured questionnaire adapted from the safe mother hood questionnaire ${ }^{12}$ developed by maternal and neonatal health program of JHPIEGO the affiliate of Johns Hopkins University was utilized for data collection following institutional approval from University of Benin Teaching Hospital and informed consent from respondents. Data was coded, entered and analyzed using SPSS version 16.0.

\section{Results}

Table 1 shows that the mean age of the male respondents interviewed was $37.8 \pm 9.9$ years, 216(85.7\%) were married and $2(0.8 \%)$ of respondents were single. The median number of children by respondents was one; though a higher proportion of respondents $150(59.5 \%)$ had $1-4$ children. Christianity $246(87.7 \%)$ was the predominant religion, while a below average proportion of the respondents $123(48.8 \%)$ had completed secondary level of education while $6(2.4 \%)$ none. In relation to the socio-economic classification (SEC) of respondents, majority 191(75.8\%) were in Upper SEC and 61 (24.2\%) in Lower SEC.

Thirty three (13.9\%) spouse/male partners accompanied their wife for antenatal (ANC) visit while 205(86.1\%) of them did not. While in relation to the frequency of ANC attendance, majority $32(97.0 \%)$ accompanied their wives sometimes for antenatal visits while only $1(3.0 \%)$ always did (See Table 2$)$

In relation to source of funds, personal savings and spouse or male partners $34(45.9 \%)$ was the predominant source of money during pregnancy among pregnant women, followed by personal savings alone $27(36.5 \%)$ and the least being from spouse or male partners $13(17.6 \%)$ (See Table 2)

During labour, a total of $127(55.0 \%)$ pregnant women were accompanied to the place of delivery by their spouse /male partners while 104 (45.0\%) were not (See Table 2)

In relation to danger signs in pregnancy and labour Table 3 shows that, vaginal bleeding $237(100 \%)$, blurred vision $227(95.6 \%)$, convulsion $228(96.2 \%)$, severe weakness $225(95.2 \%)$ and severe abdominal pain $228(96.2 \%)$ were the most commonly reported danger signs in pregnancy with the least being nausea and vomiting 64(27.0\%). Also, severe vaginal bleeding 237 (100.0\%) and convulsion 236(99.6\%) were the most commonly reported danger signs in labour with the least being constipation 74(31.2\%).

While in relation to danger signs in the newborn and new born care Table 4 showed that majority of the responses included 229(96.8\%) for difficulty in breathing, 231(97.6\%) Jaundice, 227(96.0\%) poor sucking and 237 (100.0) bleeding or discharge from the umbilicus, with least mentioned $42(17.7 \%)$ being pinkish skin.

The predominantly mentioned care new born should receive were eye care 250(99.0\%), Cord care $244(96.8 \%)$, followed by exclusively breast feeding $237(94.0 \%)$ and least 208 (82.5\%) being appropriate clothing.

Finally, in relation to community involvement in BPACR Table 5 showed that, awareness of community services was low $17(6.7 \%)$ among respondents, with community transport services $14(82.4 \%)$ being the predominant form of community support followed by community blood donation services $2(11.8 \%)$, and community finance $1(5.9 \%)$ being least.

\section{Discussion}

This study identified low level of male attendance during ANC with increased attendance reported during labour. Other studies, Ekiadolor ${ }^{13}$ Edo State, Northern Nigeria ${ }^{6}$, El Salvador ${ }^{2}$ Central America and Greece $^{3}$ equally showed low levels of male involvement during ANC which increased during labour. These studies were purely male studies and data collections were quantitative, except for the Ekiadolor study ${ }^{13}$ which was purely a qualitative study and involved female respondents to help cross check the reported findings from male participants. 
Antenatal care attendance alone is not sufficient to indicate that men are supporting their partners, financial support, prompt and proper decision making especially in the area of maternal and child health care should also be considered. The low level of male participation identified in this study could be due to a higher ANC registration by pregnant women in public health facilities than private health facilities which had a more defined time schedule for ANC sessions. Antenatal sessions usually coincides with regular formal working hours especially during week days, this may not be convenient for spouses and male partners of pregnant women at such times due to other competing interests of work and business. Also, ANC sessions are usually more flexible in private health facilities; they are more willing to attend to their ANC clients at any time of the day and night including weekends apart from the prescheduled week day dates and this flexibility may encourage better male attendance. In our society ANC is seen as a woman affair and this may have equally contributed to the low ANC attendance by males in this study, interestingly some women may not be comfortable with their husband being around them for ANC who should be up about more business like activities.

The low level of male attendance identified in this study is in contrast to research finding from other studies in Osun State $e^{6}$ and Ibadan ${ }^{7}$ South Western, which revealed a high level of awareness of emergency obstetric condition by men and male involvement in ANC and delivery respectively. In relation to pregnancy signs and labor pains, the men played useful roles during their partner's obstetric conditions and the women were able to make key decisions during emergency obstetric conditions in the absence of their male partner ${ }^{6}$. The study showed that education was a key determinant of male knowledge and behavior. There is no doubt that knowledge of danger signs in pregnancy, labor, and after delivery is a key factor to reducing delays in prompt decision making to seeking help during emergency situation. ${ }^{14}$

In addition, Ugandan Studies ${ }^{1,5}$ showed high level of male involvement among pregnant women that had birth plans, as they were more likely to be accompanied by their spouse for ANC attendance and labour. These studies revealed that men who accompanied their wives for ANC were knowledgeable about antenatal services and obtained health information directly from health workers than those who did not accompany their wife for ANC. Those who utilized skilled attendants in previous pregnancy were more likely to utilize same in index pregnancy.

Although male attendance during ANC was low in this study, the level of attendance improved during labour, given the idea that men are aware of the importance of their being around during labour or emergency. The knowledge of danger signs in pregnancy, labour, newborn and new born care was equally high. This level of knowledge of danger signs can become useful during times of emergency when decisions must be taken and on time.

The existence of community-level support systems to provide emergency funds, transport, and blood donor support services are vital in promoting maternal and newborn survival ${ }^{12}$. Community leadership therefore has an important role to play in removing barriers in deciding to seek care and improving access to skilled attendants for women and their newborn babies. An emergency response system must be put in place and made known to the public. If women living in a community are ignorant of the existence of these emergency response systems, they are unlikely to use and benefit from them. Also a system for identifying pregnant women through community-based health promoters will ensure that support/help is given when needed. ${ }^{14}$

This study identified low level of community involvement with regard to BPACR in the communities studied, with transportation being the predominant form of assistance rendered to pregnant women.Though informal interaction with some community members showed that community involvement was not existent in most of the communities studied. The respondents reported that no such scheme was on ground to address transportation challenges, emergency fund nor community blood donation services and that services initially identified, were usually from family members, friends and neighbors and not necessarily as organized effort by their respective communities. Similarly, a study ${ }^{12}$ in India revealed a low level of community participation in birth preparedness and complication readiness especially in the area of transportation. Some of the respondents affirmed that the community made special arrangement for transport of pregnant during labour and emergency situations ${ }^{12}$.

This has serious implication for health care service delivery as the community should provide the needed support structure for family members and individuals which can provide a good avenue for community health insurance scheme. These communities may therefore, lack the needed ownership mentality required for their public health facilities and may not protect it as their own, further exposing these health facility and staff to the dangers of burglary and perhaps not benefitting from the protection that such facilities would have enjoyed from the host community. These communities may then fail to patronize the services from the public health facilities; as such utilize the services provided by private health facilities with the attendant high health cost from out of pocket expenditure. This has become a major challenge to people seeking healthcare from health facilities. 


\section{Conclusions}

This study identified low level of male involvement with regard to BPACR with marked improvement in attendance being reported during labour/emergencies as against ANC attendance. Furthermore, male respondents were knowledgeable about the danger signs in pregnancy, labour and newborn including newborn care. Finally, a low level of community involvement was also identified in this study with transportation being the predominant form of assistance rendered to pregnant women.

\section{Recommendations}

Men should show better involvement in reproductive health activities, especially in the area of ANC attendance and delivery, including other areas such as assisting spouse to identify health facility for care, identifying skilled attendants at birth, making adequate financial and transport preparation towards child birth and emergencies.

Community support structures should be established in the area of transportation, blood donation and finance exploring avenues such as community health insurance scheme and other financial schemes such as "Osusu", these can help increase their pool of emergency funds. This fund during emergencies can help reduce "out of pocket" expenditures and the attendant consequences to seeking and receiving care.

\section{Limitation of Study}

The findings of this study were based on self reporting as it may be difficult verifying claims by respondents.

\section{Acknowledgement}

We wish to express appreciation to all respondents who participated in this study, project supervisor (Prof.(Mrs) O.H. Okojie), research assistants and the Management of the University of Benin Teaching Hospital for their support both financial and otherwise in ensuring the success of this study, we remain most grateful.

\section{References}

[1]. Kakaire O, Kaye DK, Osinde MO. Male involvement in Birth Preparedness and Complication Readines for emergency Obstetric referrals in Rural ,Uganda.Reprod health. 2011; 8;12 doi : 10.1186/1742 - 4755 -8-12

[2]. Iliyasu Z, Abubakar IS, Galadanci HS, Aliyu MH. Birth preparedness ,Complication Readiness and Fathers' participation in Maternity care in a Northern Nigerian Community.Afr J Reproductive Health $2010 ; 14$ (1) : 22 - 32

[3]. Carter MW, Speizer I. Salvoran Fathers' attendance at prenatal care, delivey and post partum care. Rev Panam Salud Publica. 2005 ; 18 (3) : $149-56$

[4]. Dragonas TG. Greek Fathers' participation in labour and care of the infant. Scand J Caring Sci. 1992;6 (3) : 151-9.

[5]. Tweheyo R, Konde-Lule J, Tumwesigye NM, Sekandi JN. Male partner attendance of skilled antenatal care in peri-urban Gulu district, Northern Uganda. BMC Pregnancy and Childbirth. 2010;10: 53

[6]. Odimegwu C, Adewuyi A, Odebiyi T, Aina B , Adesina Y, Olatubara O and Eniola F. Men's Role in Emergency Obstetric Care in Osun State of Nigeria. Afr J Reproductive Health 2005 ; 9 (3) : 59 - 71.

[7]. Olayemi O, Bello FA, Aimakhu CO, Obajimi,Adekunle AO. Male participation in pregnancy and Delivery in Nigeria:A survey of Antenatal clinic attendees.Journal of Biosocial Sciences $2009 ; 41: 493-503$.

[8]. Nandan D,Kushwah SS, Dubey DK. A study for assessing Birth Preparedness and Complication Readiness Intervention in Rewa District of Madhya Pradesh, India.2008 p 1-34.

[9]. Eni-Meg Nigeria Limited. Edo State Investors' Guide ( $1^{\text {st }}$ Edition International). Eni-Meg. Publishers, Lagos, $1999: 2-256$

[10]. Edo State Ministry of Health. Department of Hospital services, List of Health Facilities

[11]. Cochran WG. Sampling techniques (3rd ed.).1977.New York: John Wiley \& Sons

[12]. JHPIEGO. Maternal and neonatal health. Monitoring birth preparedness and complication readiness, tools and indicators for maternal and newborn health. Johns Hopkins, Bloomberg school of Public Health, Center for communication programs, Family Care International; 2004

[13]. Adeleye OA, Chiwuzie J. 'He does his own and walks away' Perception about male attitudes and practices regarding safe motherhood in Ekiadolor, Southern Nigeria. African Journal of Reproductive Health .11(1).April, 2007.

[14]. JHPIEGO. Maternal and neonatal health $(\mathrm{MNH})$ program. Birth preparedness and complication readiness: A Matrix of shared responsibilities. Baltimore, MD: JHPIEGO; 2001. p. 12 
APPENDIX

Table 1: Socio-Demographic Characteristics of Spouse/Male Partners and Family Members

\begin{tabular}{|c|c|c|c|}
\hline Variable & & Frequency $(n=252)$ & Percent \\
\hline \multicolumn{4}{|l|}{ Age Group(Years) } \\
\hline $15-24$ & & 2 & 0.8 \\
\hline $25-34$ & & 101 & 40.1 \\
\hline $35-44$ & & 106 & 42.1 \\
\hline $45-54$ & & 28 & 11.1 \\
\hline $55-64$ & & 15 & 5.9 \\
\hline \multicolumn{4}{|l|}{ Marital Status } \\
\hline Single & & 2 & 0.8 \\
\hline Married & & 216 & 85.7 \\
\hline Separated & & 3 & 1.2 \\
\hline Widowed & & 9 & 3.6 \\
\hline Cohabiting & & 22 & 8.7 \\
\hline \multicolumn{4}{|l|}{ No of Children } \\
\hline$\leq 1$ & & 72 & 28.6 \\
\hline $1-4$ & & 150 & 59.5 \\
\hline$>4$ & & 30 & 11.9 \\
\hline \multicolumn{4}{|l|}{ Religion } \\
\hline Christianity & & 246 & 97.6 \\
\hline Islam & & 4 & 1.6 \\
\hline ATR & & 2 & 0.8 \\
\hline \multicolumn{4}{|c|}{ Educational Status } \\
\hline None & & 6 & 2.4 \\
\hline $1^{0}$ Completed & & 50 & 19.8 \\
\hline $2^{0}$ Completed & & 123 & 48.8 \\
\hline $3^{0}$ Completed & & 73 & 29.0 \\
\hline $\begin{array}{l}\text { Socio-Economic } \\
\text { (SEC) }\end{array}$ & Class & & \\
\hline Upper SEC & & 191 & 75.8 \\
\hline Lower SEC & & 61 & 24.2 \\
\hline
\end{tabular}

Table 2: Male involvement in Relation to Birth Preparedness

\begin{tabular}{|c|c|c|}
\hline Aspects of Male involvement & Frequency $(n=237)$ & Percent \\
\hline \multicolumn{3}{|l|}{ Male Attendance at ANC $(n=237)$} \\
\hline Yes & 33 & 13.9 \\
\hline No & 204 & 86.1 \\
\hline \multicolumn{3}{|l|}{ Frequency of ANC Visits $(n=33)$} \\
\hline Always & 1 & 3.0 \\
\hline Sometimes & 32 & 97.0 \\
\hline \multicolumn{3}{|l|}{ Source of funds $(n=74)$} \\
\hline Spouse Or Male Partners & 13 & 17.6 \\
\hline Personal Savings & 27 & 36.5 \\
\hline Personal Savings and Spouse or Male Partners & 34 & 45.9 \\
\hline \multicolumn{3}{|l|}{ Company during Labour $(n=231)$} \\
\hline Spouse/Male Partner & 127 & 55.0 \\
\hline *Others & 104 & 45.0 \\
\hline
\end{tabular}

Table 3: Knowledge of Danger Signs* during Pregnancy and Labour by Spouse/Male Partners Danger Signs* Frequency $(n=237)$ Percent

Danger Signs* in Pregnancy

Vaginal bleeding $\quad 237 \quad 100.0$

$\begin{array}{lll}\text { Severe headache } & 218 & 92.0\end{array}$

$\begin{array}{lll}\text { Blurred vision } & 227 & 95.8\end{array}$

General body weakness $\quad 111 \quad 46.8$

$\begin{array}{lrl}\text { Convulsion } & 228 & 96.2\end{array}$

Swollen leg and face $\quad 116 \quad 48.9$

$\begin{array}{lll}\text { High fever } & 206 & 206.9\end{array}$

\begin{tabular}{lrr} 
Loss of consciousness & 218 & 92.0 \\
\hline
\end{tabular} 
Male And Community Involvement In Birth Preparedness And Complication Readiness In Benin City,

\begin{tabular}{lrr}
\hline Nausea and vomiting & 64 & 27.0 \\
Difficulty breathing & 192 & 81.0 \\
Severe weakness & 225 & 94.9 \\
Severe abdominal pain & 228 & 96.2 \\
Accelerated and reduced fetal movement & 215 & 90.7 \\
Water breaks without labour & 187 & 78.9 \\
Danger Signs*in Labour & & \\
Severe vaginal bleeding & 237 & 100.0 \\
Severe headache & 217 & 91.6 \\
Frequent urination & 116 & 48.9 \\
Convulsion & 236 & 99.6 \\
High fever & 219 & 92.4 \\
Loss of consciousness & 212 & 89.5 \\
Painful uterine contraction & 119 & 50.2 \\
Labour lasting greater than 12 Hours & 201 & 84.8 \\
Placenta not delivered after 30 minutes & 202 & 85.2 \\
Constipation & 74 & 31.2 \\
Could a woman die from this problem & 237 & 100 \\
\hline
\end{tabular}

*Multiple responses

Table 4: Knowledge of Danger Signs* in the Newborn and Newborn care by Spouse/Male partners

\begin{tabular}{lrr}
\hline Knowledge of Newborn Care/Danger Signs & Frequency(n=237) & Percent \\
\hline Danger signs* & & \\
Difficult or fast breathing & 229 & 96.6 \\
Jaundice & 231 & 97.5 \\
Poor sucking or feeding & 227 & 95.8 \\
Bleeding or discharge from the umbilicus & 237 & 100.0 \\
Baby very small & 194 & 81.9 \\
Convulsions and spasms rigidity & 202 & 85.2 \\
Pinkish skin & 42 & 17.7 \\
Lethargy/unconsciousness & 216 & 91.1 \\
Red or swollen eyes with pus & 222 & 93.7 \\
New born care* & & \\
Exclusive Breastfeeding & 225 & 94.9 \\
Appropriate Clothing & 197 & 83.1 \\
Eye Care & 236 & 99.6 \\
Cord Care & 230 & 97.0 \\
\hline
\end{tabular}

*Multiple responses

Table 5: Awareness and type of Community Support* in relation to BPACR as reported by pregnant women $(\mathbf{n}=\mathbf{2 5 2})$

\begin{tabular}{llc}
\hline Variable & Frequency(n=252) & Percent \\
\hline Awareness of community services & 17 & 6.7 \\
Yes & 235 & 93.3 \\
No & & \\
& & 82.4 \\
Type of community support* $(\mathbf{n}=\mathbf{1 7})$ & 14 & 11.8 \\
Transport Services & 2 & 5.9 \\
Blood Donation Services & 1 & \\
Finance & & \\
\hline
\end{tabular}

*Multiple responses 